\title{
SIRT1/SIRT3 Modulates Redox Homeostasis during Ischemia/Reperfusion in the Aging Heart
}

\author{
Jingwen Zhang ${ }^{1,2} \mathbb{D}$, Di Ren ${ }^{2}$, Julia Fedorova ${ }^{2}$, Zhibin $\mathrm{He}^{2}$ and $\mathrm{Ji} \mathrm{Li}^{2, * \mathbb{C}}$ \\ 1 College of Life Sciences, Shandong Normal University, Jinan 250014, China; jzhang14@usf.edu \\ 2 Department of Surgery, Morsani College of Medicine, University of South Florida, Tampa, FL 33612, USA; \\ diren@usf.edu (D.R.); jfedorova@usf.edu (J.F.); zhibin@usf.edu (Z.H.) \\ * Correspondence: jili@usf.edu; Tel.: +1-813-974-4917
}

Received: 2 July 2020; Accepted: 8 September 2020; Published: 13 September 2020

\begin{abstract}
Ischemia/reperfusion (I/R) injury is the central cause of global death in cardiovascular diseases, which is characterized by disorders such as angina, stroke, and peripheral vascular disease, finally causing severe debilitating diseases and death. The increased rates of morbidity and mortality caused by I/R are parallel with aging. Aging-associated cardiac physiological structural and functional deterioration were found to contribute to abnormal reactive oxygen species (ROS) production during I/R stress. Disturbed redox homeostasis could further trigger the related signaling pathways that lead to cardiac irreversible damages with mitochondria dysfunction and cell death. It is notable that sirtuin proteins are impaired in aged hearts and are critical to maintaining redox homeostasis via regulating substrate metabolism and inflammation and thus preserving cardiac function under stress. This review discussed the cellular and functional alterations upon I/R especially in aging hearts. We propose that mitochondria are the primary source of reactive oxygen species (ROS) that contribute to $\mathrm{I} / \mathrm{R}$ injury in aged hearts. Then, we highlight the cardiomyocyte protection of the age-related proteins Sirtuin1 (SIRT1) and Sirtuin1 (SIRT3) in response to I/R injury, and we discuss their modulation of cardiac metabolism and the inflammatory reaction that is involved in ROS formation.
\end{abstract}

Keywords: ischemia and reperfusion; SIRT1; SIRT3; ROS; aging heart

\section{Introduction}

Ischemic heart disease, symbolized by the constriction in the coronary blood vessel, is one of the most significant cardiac problems with a higher death rate among the elderly population [1]. Compared to adult hearts, aged hearts are more vulnerable to ischemic insults and sustain greater injury during ischemia/reperfusion (I/R) [2]. In clinical, aging augmented in vivo reactive oxygen species (ROS) levels in acute myocardial infarction (AMI) patients [2]. The findings of proteomics analyses showed that the downregulation of elevated mitochondrial ROS levels protects old mice against age-related decline, supporting the theory that decreased ROS levels could be a beneficial factor on the extension of life span in the elder population [3-5]. Uncontrolled cardiac ROS generation caused by pathological alterations involved in myocardial I/R injury can promote oxidative damage to cellular proteins and other biomolecules, as well as mitochondrial dysfunction and cell death [6]. These discoveries advance the understanding of the mechanisms of abnormal redox homeostasis in order to develop potentially effective approaches to protect hearts from I/R injury, especially in the older population.

Sirtuins are a family of highly conserved proteins with homology to the yeast silent information regulator 2 (SIR2). Growing studies have implicated that sirtuins play vital roles in delaying cellular senescence and extending mammal lifespan [7]. Since they were identified in mammals, sirtuins have been implicated in many essential cellular processes and functions, including longevity [8], DNA damage repair [9], metabolism [10], and inflammation [11]. Sirtuin1 (SIRT1) has an evolutionary 
relationship to SIR2 and has been most intensively investigated in the cardiovascular system with effective deacetylase activity controlling cellular processes such as cell apoptosis, autophagy, and cell proliferation [12,13]. SIRT1 can diminish oxidative stress by activating cardioprotective molecules and inhibit apoptosis-related signaling pathways against cardiac I/R [14]. Sirtuin3 (SIRT3), as the central control of mitochondrial protein deacetylation, protects cardiomyocytes from aging and oxidative stress [15-18]. SIRT3 deficiency aggravates the cardiac susceptibility to I/R stress with severe mitochondria abnormalities and exacerbates a higher level of myocardial I/R injury with aging $[19,20]$.

In this review, we will mainly focus on the functions of age-related sensors SIRT1 and SIRT3 via modulating redox homeostasis in response to myocardial I/R stress. This makes them potential targets for developing better cell-based therapeutic strategies for elderly patients against I/R-induced injury.

\section{Role of Longevity Gene Sirtuins in Myocardial $I / R$}

Sirtuins are mammalian homologs of yeast Sir2, a silent information regulator 2, which has the capacity to deacetylase numerous proteins in a nicotinamide adenine dinucleotide $\left(\mathrm{NAD}^{+}\right)$-dependent manner $[10,21]$. To date, seven members of the sirtuin family have been reported in mammals with various enzymatic activity and subcellular localization. All of them have the common catalytic domain that consists of 275 amino acids accounting for protein deacetylation [22,23]. In addition, ADP ribosylation is the main activity for Sirtuin4 (SIRT4) instead of deacetylase activity, which is also typical for Sirtuin6 (SIRT6) [24,25]. In addition, Sirtuin5 (SIRT5) has weak deacetylase activity but effective demalonylase and desuccinylase activity [26,27].

SIRT1, SIRT6, and Sirtuin7 (SIRT7) localize predominately in the nucleus, and more evidence regarding SIRT1 and SIRT6 but not SIRT7 are reported to imply important functional links to aging $[28,29]$. The elimination of SIRT1 expression causes only $50 \%$ of individuals to be born and only $20 \%$ to survive to maturity in mouse models. Such mice have developmental defects with phenotypic abnormalities in the eye and heart [30]. Furthermore, overexpressing SIRT1 in the mice hypothalamus can increase the lifespan by $16 \%$ in females and $9 \%$ in males [31]. Sirtuin 2 (SIRT2) can be found mostly in the cytoplasm, and SIRT3, SIRT4, and SIRT5 are located in mitochondria [23]. SIRT3 is thought to be the central control of mitochondrial protein deacetylation due to the hyperacetylation of global mitochondrial proteins in the absence of SIRT3, but not SIRT4 or SIRT5 [32]. More interestingly, SIRT3 is the only sirtuin that has been reported to impact longevity in humans based on the fact that a certain polymorphism in the SIRT3 gene can be found more often in elder people [33,34]. SIRT3 has exhibited the capacity to reverse aging-associated degeneration via the control of mitochondrial homeostasis consistently [35]. Taken together, these results support that sirtuins play critical roles in maintaining mammalian longevity.

Sirtuins have beneficial roles in regulating cellular homeostasis with aging in a wide range of cardiovascular diseases including myocardial I/R [10]. For example, SIRT1 possesses many capabilities to protect hearts from myocardial I/R injury, including maintaining redox and metabolic homeostasis [36], repressing inflammatory reaction [37], inhibiting apoptosis [14], and promoting autophagy [38]. In our I/R model of cardiac specific SIRT1 knockout mice, the heart showed significantly enlarged infarction size, metabolic disorder, and excessive cardiac ROS levels [36]. We also found that the deletion of SIRT1 in cardiomyocytes caused the hyperacetylation of liver kinase B1 (LKB1) and impaired the phosphorylation of adenosine monophosphate protein kinase (AMPK) during ischemia [36]. These promote the significance of SIRT1 in the repression of energetic consuming processes via LKB1/AMPK during I/R stress. Moreover, SIRT1 deficiency leads to inflammatory-like phenotype alterations in the heart during $\mathrm{I} / \mathrm{R}$ as well as upregulated inflammatory cytokines such Interleukin- $1 \beta$ (IL-1 $\beta$ ), Tumor necrosis factoas- $\alpha$ (TNF- $\alpha$ ) and Interleukin-6 (IL-6) during I/R injury [14,37], which is caused by the activation of the Nod-like receptor protein-3 (NLRP3) inflammasome. SIRT1 is also a potential target for cardiac apoptosis during I/R. It has been proven that the SIRT1-induced inhibition of p53 transcription is closely involved in the survival of cardiomyocytes, since p53-mediated apoptosis was activated as a result of the decreased SIRT1 during cardiac ischemia [14,39]. Furthermore, 
SIRT1-related autophagic regulation has been recognized to maintain cardiac function as the result of the deacetylation of autophagy-related protein (ATG) family members, such as ATG5, ATG7 and ATG8, and forkhead box class O protein (FoxO) [38].

The underlying role of SIRT3 in the alleviation of I/R injury in the heart is mainly related to the post-translational modification of mitochondrial bioenergetic processes [40]. Defected cardiac SIRT3 level causes an upregulation of ROS generation and the hyperacetylation of proteins associated with mitochondria oxidative phosphorylation (OXPHOS), fatty acid oxidation, and the tricarboxylic acid (TCA) cycle, as well as oxidative stress [20]. Recent research revealed the three ways that SIRT3 regulates cardiac autophagy during I/R stress, which are autophagosome formation-related AMPK/mTOR activation, the Foxo3a-mediated Pink1/Parkin pathway, and mitochondrial ROS homeostasis via superoxide dismutase 2 (SOD2) [41,42]. In this way, SIRT1 and SIRT3 have multiple beneficial effects on protecting hearts against I/R injury and suggest the significance of them as potential targets for cardioprotection, especially in the elder population. Considering the importance of ROS, which are primary toxic by-products of aerobic metabolism that lead to macromolecular damage in cardiovascular disease [6], this review focuses on summarizing the latest evidence regarding the role of SIRT1 and SIRT3 in redox homeostasis during cardiac I/R stress.

\section{Reactive Oxygen Species in Age-Related Ischemic Heart Disease}

ROS consist of unstable molecules containing oxygen with high instability and a short half-life [43]. They are physiologically related to regulate cellular homeostasis and mediate signal transduction for cardiac development, contractile function, and calcium handling [44]. Cardiac mitochondria are significantly abundant, and the high adenosine triphosphate (ATP) consumption of the beating heart depends on the oxidative energy generated by the mitochondria electron transport chain (ETC) [45]. Mitochondria ETC is the major endogenous source of the ROS (especially superoxide and hydroxyl radical) [46,47], especially complex I and III [48]. Complex I, as first enzyme of mitochondria ETC, catalytically transfers two electrons from the nicotinamide adenine dinucleotide hydride (NADH) matrix to coenzyme $\mathrm{Q}(\mathrm{CoQ})$ and leaks electrons to $\mathrm{O}_{2}$ [49]. The crystal structure of the hydrophilic domain in complex I [50] reveals that most of the cofactors in the enzyme are shielded from solvent. Therefore, it is most likely that $\mathrm{O}_{2}$ accesses complex I and produces superoxide through the two sites, site $\mathrm{I}_{\mathrm{F}}$ (FMN site) and site $\mathrm{I}_{\mathrm{Q}}$ (CoQ binding site), and then releases ROS to the matrix [51,52]. Complex III is another critical place for electron leakage through the Q-cycle resulting in superoxide production in the Qo site and releasing ROS into both the mitochondrial matrix and intermembrane space [53-55]. In this process, ubisemiquinone in the Qo site carries a single electron and directly transfers to $\mathrm{O}_{2}$ in complex III, generating superoxide via a nonenzymatic reaction $[49,56]$.

Mitochondrial dysfunction, especially the impairment of ETC, is one of the important factors involved in cardiac dysfunctions induced by I/R injury. Upon myocardial ischemia, limited oxygen availability is intimately related to the mitochondrial OXPHOS arrest, leading to dramatically reduced ATP synthesis $[57,58]$. In order to counterbalance this situation, the troubled cardiomyocytes switch to anaerobic glycolysis to meet the metabolic demand accompanied with the aggregation of protons and lactate, eventually resulting in decreasing the intracellular $\mathrm{pH}$ [59] and promoting calcium overload in the cell $[60,61]$. ROS generation is associated with increased electron leakage as a result of impaired ETC, especially within three minutes of ischemia [62,63]. Ischemia directly increased the production of oxyradicals generated by complex I with compromised activity in the first 10-20 min [64]. During ischemia, the functional change of the Qo site in complex III can disturb the electron flux, leading to increased ROS production [65]. Reperfusion was characterized by a sudden restoration of oxygen delivery, and the ATP generation was rapidly switched from anaerobic glycolysis to aerobic mitochondrial OXPHOS with removing accumulated $\mathrm{H}+$ in the extracellular space [66,67]. Although reperfusion intervention is the most effective strategy to salvage the ischemic heart [68-70], there are still complications such as the generation of ROS, cytokines, and chemokines exacerbating injury via the accumulation of cellular damage and mitochondrial abnormalities [71,72]. I/R causes substantial 
mitochondria swelling and cell death, altered cardiac metabolism such as glycolysis disturbance and TCA cycle dysfunction, as well as increased inflammatory reaction [48]. The accumulation of succinate in the TCA cycle presents in the heart during ischemia, and its rapid oxidization induces the enhanced mitochondrial ROS production as the result of complex I-involved reverse electron transport (RET) during early reperfusion [6,73-75]. These highlight that the redox response during ischemia in stimulated cardiomyocytes is an indispensable element for the process of cell injury during reperfusion [76,77].

Aging is a complicated and progressive process that involves alterations in both physiology and metabolism in every organ and system $[77,78]$. Compared to young adults, elder patients have diastolic dysfunction with a lower ratio of the early to late ventricular filling velocities (E/A) and a longer left ventricular isovolumetric relaxation time (LVRT) [79]. In addition, the cardiac systolic function which presents by ejection fraction (EF) and fractional shorting (FS) show a significant decrease in response to $\mathrm{I} / \mathrm{R}$ stress along with aging $[80,81]$. The hearts lose the capacity to recover from ischemia in clinical settings with a lower survival rate in old patients [82]. Animal experiments also showed blunted functional recovery and enlarged infarct size following $\mathrm{I} / \mathrm{R}$ in the aged heart $[36,83,84]$. Thus, it is critical to understand the mechanisms of the increased myocardial damage caused by $\mathrm{I} / \mathrm{R}$ in the aged heart in order to develop potentially effective strategies for myocardial protection.

Diminished mitochondria electron transport chain (ETC) activity and elevated ROS production contribute significantly to the pathogenesis of aging hearts, leading to increased oxidative damage, including lipid peroxidation and mtDNA damage [22,85-89]. Thus, mitochondria, as the main source of ROS, are a potential cause for the increased injury in the aged heart [90-92]. A previous study demonstrated that ischemic damage increased the formation of oxyradicals conducted by complex III in the aging heart which overlapped with the pre-existing aging defects [91]. Increased myocyte apoptosis and the oxidative modification of mitochondrial proteins also supports the greater mitochondria-derived oxidative damage in the aged heart during $\mathrm{I} / \mathrm{R}[93,94]$. Moreover, the impairment of mitochondrial OXPHOS and the excessive ROS with aging during myocardial I/R exacerbates impaired metabolic flexibility [93], resulting in more severe contractile dysfunction [95] and the intolerance to $\mathrm{I} / \mathrm{R}$ stress in the aged heart $[36,84,93]$. These findings prompt a close relationship between ROS and age-related cardiac dysfunction upon I/R stress, and an effective therapeutic management in substrate metabolism is essential to protect myocardium from $\mathrm{I} / \mathrm{R}$ injury, in particular for the elderly. However, a recent study has observed elevated levels of substrate metabolites but no transcriptional changes in energy metabolic pathways in early heart failure [96]. It suggests that the post-translational modifications contribute to the alterations in energy metabolism that occur in the early stages of heart disease. As a major post-translational modification for cellular signaling, protein acetylation and deacetylation is regulated by deacetylase, such as sirtuin proteins. The activity of sirtuins is coupled with the cellular $\mathrm{NAD}^{+}$level, indicating their close relationship between cellular energy and redox status. Thereby, we will mainly focus on the deacetylase functions of longevity sensor SIRT1 and SIRT3 via modulating redox homeostasis in response to cardiac I/R stress.

\section{Role of SIRT1 in the Redox Homeostasis during Myocardial I/R}

SIRT1 is the closest mammalian homolog to the yeast Sir2 protein in sequence and is expressed throughout the body, for example, in adipose tissue, liver, heart, and muscle [97]. In the cardiomyocytes, SIRT1 is predominantly located in the nucleus [98]; meanwhile, SIRT1 is also reported to play important roles in cytoplasm and mitochondria fraction $[98,99]$. Alcendor et al. revealed that the overexpression of SIRT1 in mouse cardiac muscle could protect the heart from oxidative stress and alleviate age-related cardiac hypertrophy [100]. Beyond these, SIRT1 has a pivotal role in repressing inflammation and regulating the metabolic process upon stress stimulation, as well as some putative beneficial effect associated with its activation concerning its role in the lifespan extension $[36,98,101]$. It is notable that the SIRT1 protein expression level declines with aging in hearts [102]. In addition, its activity is also impaired due to the defected $\mathrm{NAD}^{+}$in aged hearts [103]. More interesting, the reduction of SIRT1 
in senescence hearts increases their susceptibility of hearts to I/R injury [20]. These results indicate that SIRT1 is indispensable in aged hearts in response to I/R stress. We next aim to summarize the roles of SIRT1 in regulating ROS-related pathways, which is critical for the modulation of substrate metabolism and inflammatory response in aged hearts during I/R injury.

SIRT1 induces a substrate metabolism shift for ATP production. SIRT1 interacts with and directly deacetylates peroxisome proliferator-activated receptor (PPAR) gamma coactivator-1 $\alpha$ (PGC-1 $\alpha)$ [104], which is a key switch of mitochondrial biogenesis and fuel usage, to increase its transcriptional activity [105] (Figure 1). As a transcriptional co-activator of the nuclear receptor PPAR $\gamma$, deacetylated PGC-1 $\alpha$ more effectively recruits transcription factor-like estrogen-related receptor $\alpha(E R R \alpha)$, to elevate its synthesis against ROS generation and damage, which are associated with glucose metabolism, fatty acid oxidation, and mitochondrial biogenesis [104,106,107]. PGC-1 $\alpha$ also regulates fuel utilization as demonstrated by an ex vivo isolated working heart experiment in which PGC-1 $\alpha^{-/-}$mice exhibited decreased palmitate oxidation with increased glucose oxidation [108]. The findings demonstrated that PGC-1 $\alpha$ deficiency may lead to mitochondrial dysfunction and disturbed oxidative metabolism. It is demonstrated that SRT1720, one specific Sirt1 activator, protects the heart from I/R injury through directly increasing the deacetylation of PGC-1 $\alpha$ [98]. Collectively, the activation of PGC-1 $\alpha$ by SIRT1 and enhanced mitochondria biogenesis may restore energy metabolism in the impaired myocardium and ameliorate I/R injury.

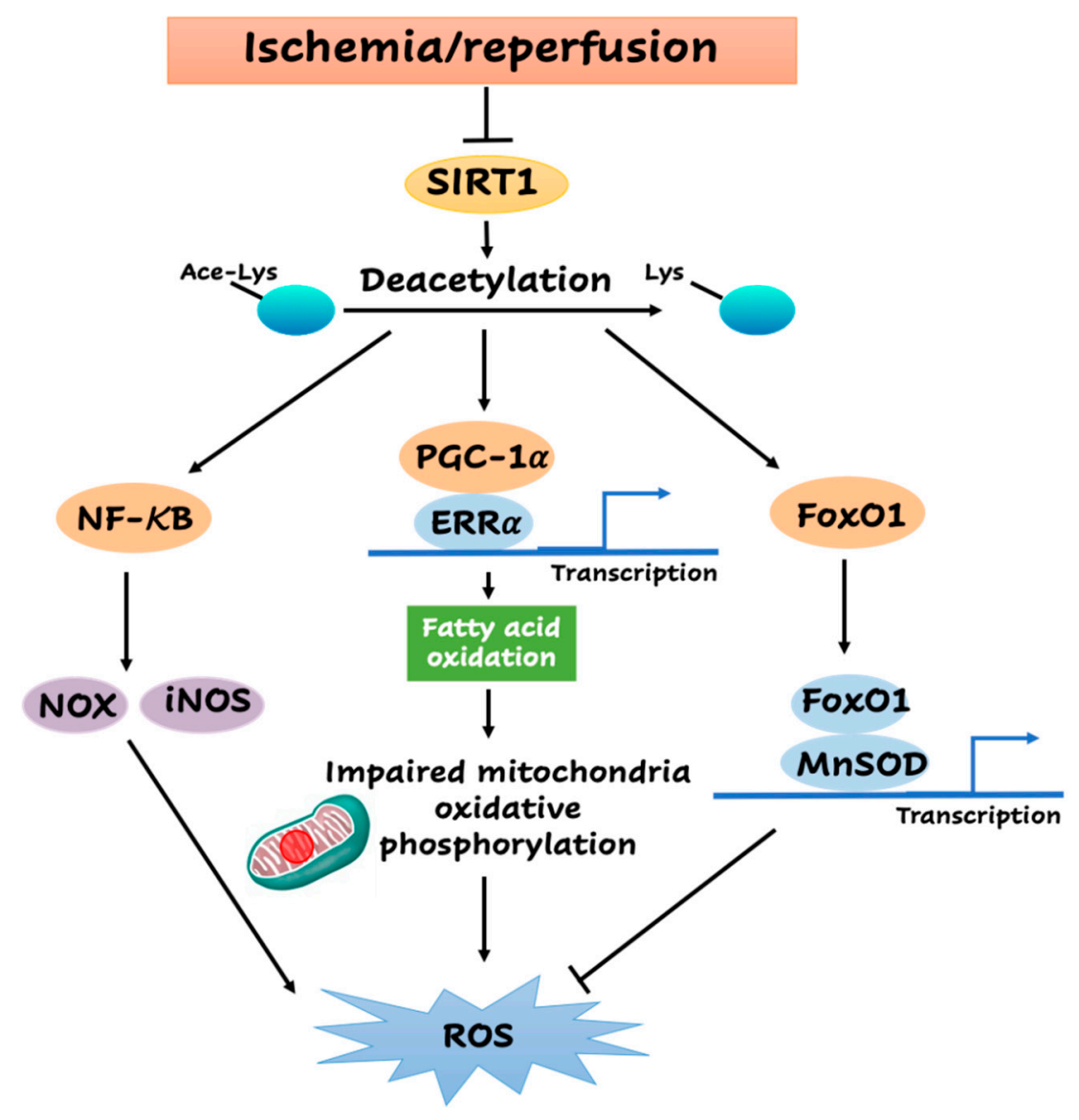

Figure 1. Sirtuin1 (SIRT1)-mediated downstream events associated with reactive oxygen species (ROS) production during myocardial ischemia and reperfusion $(\mathrm{I} / \mathrm{R})$.

SIRT1 can not only inhibit ROS generation but also influence the antioxidant defense system. FoxO1, an important forhead transcription factor in the cardiovascular system [109], participates in the process of substrate metabolism and cell proliferation [110]. SIRT1 also has the capacity to deacetylase FoxO1 and repress its transcriptional activity during $\mathrm{I} / \mathrm{R}$, which acts as a pivotal part in controlling 
the increase of manganese superoxide dismutase (MnSOD) and inhibiting oxidative stress in cardiac myocytes [111,112] (Figure 1). Consistently, the upregulation of FoxO1 was significantly enhanced with the increased expression of antioxidant MnSOD in cardiac-specific SIRT1 transgenic mice under ischemic stress [111,112]. Moreover, the increase of MnSOD induced by SIRT1 was attenuated in the FoxO1 knockdown tissues [14]. Additionally, the well-recognized immunoresponse-related nuclear factor kappa-light-chain-enhancer of activated B cells (NF-kB) signaling, which is activated during myocardial $\mathrm{I} / \mathrm{R}$, can also drive the expression of the antioxidant MnSOD [113].

In addition to mitochondria, the nicotinamide adenine dinucleotide phosphate hydrogen (NADPH) oxidases (NOX) family is another resource for cytoplasmic superoxide radicals generation [114]. As before, NF- $\mathrm{KB}$, a key factor for the immune system, participates in the transactivation of the NADPH oxidase family $[115,116]$. A substantial amount of literature indicates that the stimulation of SIRT1-related signaling attenuates myocardial I/R injury by inhibiting oxidative damage and inflammatory response [37]. In ischemic cardiomyopathy, these pathophysiological functions of SIRT1 on inflammatory reaction are mainly mediated by the deacetylation of NF- $\kappa B$ [117] (Figure 1). Both animal models and clinical surgery showed that NF-KB is activated by myocardial I/R [118,119], and its inhibition appears to contribute to a reduced infarct size [120]. These findings indicate that SIRT1 may inhibit NF- $k B$ by deacetylation, thereby repressing the ROS generated by the NOX family during I/R. Furthermore, inducible nitric oxide synthase (iNOS) is also upregulated by NF- $k B$ and thus increases the production of ROS [121], suggesting SIRT1 may be involved in the inhibition of cytoplasmic ROS produced by iNOS also. It is notable that aging appeared to be involved in the upregulation of NF- $\mathrm{KB}$ and DNA-binding activity in mouse cardiac muscle, which may be even higher in response to I/R stress $[122,123]$. These findings suggest that the impaired SIRT1 in aged hearts causes the hyperactivation of NF- $\mathrm{KB}$ in response to $\mathrm{I} / \mathrm{R}$ stress, leading to an excessive production of cytoplasmic ROS mediated by NOX and iNOS.

\section{Role of SIRT3 in the Metabolic Homeostasis during Myocardial I/R}

SIRT3 expresses at a high level in the tissues with high metabolic turnover and mitochondrial content, playing a critical effect on the heart and its role in cardiac physiology and pathology [21]. The overexpression of SIRT3 in mouse embryonic fibroblasts reduces cellular ROS by $40 \%$ [124]. However, both SIRT3-/- hearts as well as cardiomyocytes cultured from SIRT3-deficient hearts exhibit increased ROS levels $[19,125]$. These data raise the concept that SIRT3 plays a very important role in the cardiac ROS level. The protein level and activity of SIRT3 also decrease with aging in hearts due to the defected $\mathrm{NAD}^{+}[20,126,127]$. The deficiency of SIRT3 in aging hearts increases their sensitivity to ischemic insults and I/R injury [19]. Thus, understanding the mechanism of SIRT3 in regulating ROS-related pathways during myocardial I/R injury is important for revealing its role in aged hearts.

As has been shown, plenty of SIRT3 studies revealed its function coupled with cardiac metabolism [128] (Figure 2). In the heart, increased pyruvate dehydrogenase (PDH) protein acetylation with the defected SIRT3 is associated with the inhibition of its activity [129-131]. A few studies have shown that PDH contributes to ROS generation by controlling the glucose metabolism step from pyruvate to acetyl coenzyme A (acetyl-CoA) first entering TCA cycle [132,133]. In isolated rat hearts, the low ATP/Adenosine diphosphate (ADP) ratio during ischemia limited the phosphorylation of PDH and kept only 45\% PDH activation of the total enzyme content [134]. The impairment of PDH activity upon early reperfusion may due to the observed high levels of NADH and acetyl CoA and then returned slowly after following reperfusion [134-136]. It also has been implicated that the attenuated SIRT3 would lead to the hyperacetylation of long-chain acyl CoA dehydrogenase (LCAD) to the suppressed activity in heart and aging liver $[99,126]$. LCAD controls the first entry of acetyl CoA generated by fatty acid oxidation to the TCA cycle and assists ROS generation. During the reperfusion period, fatty acid oxidation recovers quickly and dominates as a source of oxygen consumption, as well as ROS generation. Due to the essential roles of PDH and LCAD in modulating glucose and fatty acid oxidation and the following contribution to ROS generation, the role of SIRT3 involved in 
deacetylating PDH and LCAD could be a way to control the metabolic balance and ROS generation during myocardial I/R. However, Muoio group recently reported that SIRT3 deletion has no impact on mitochondrial respiratory function [137] but may alter the local redox environment.

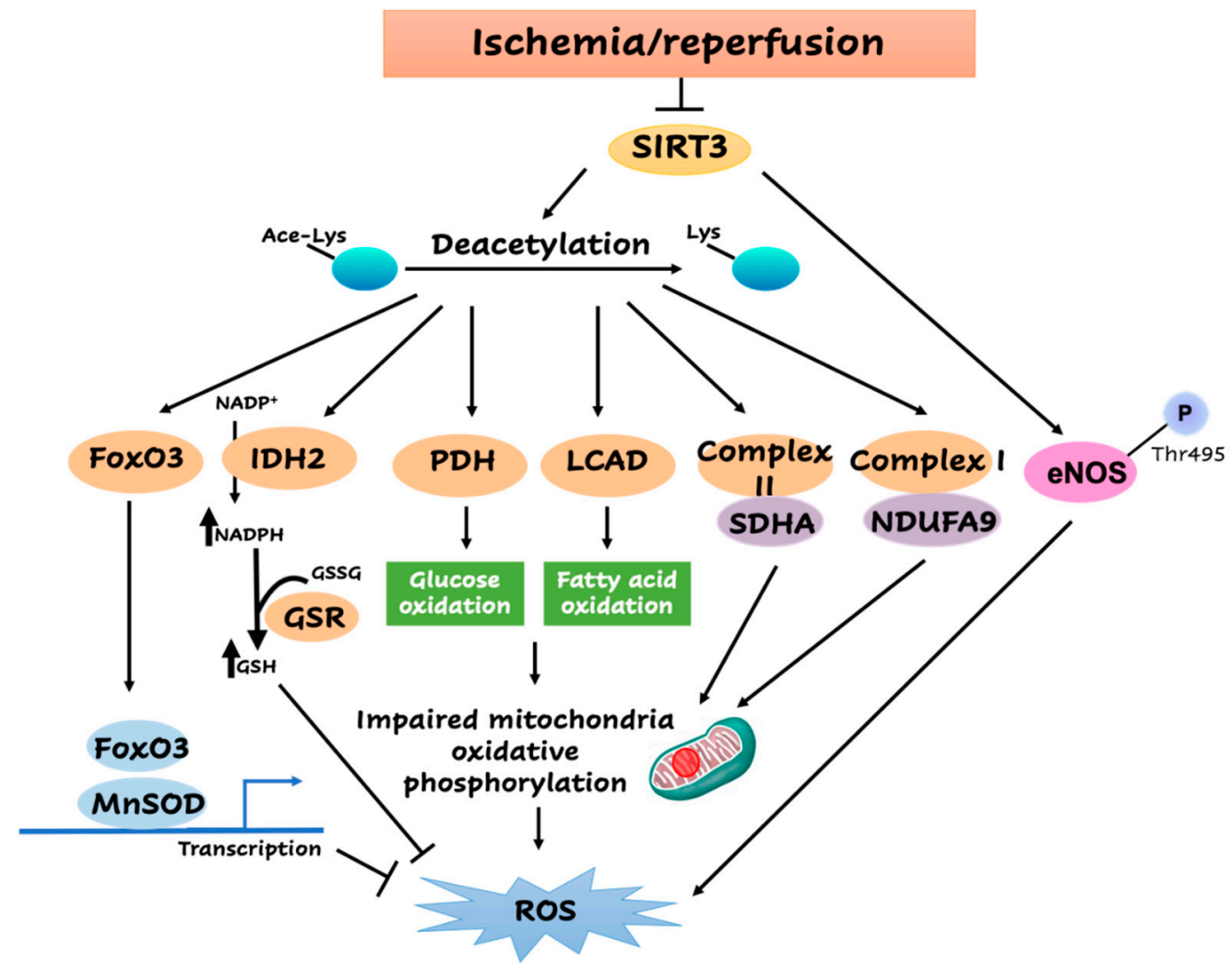

Figure 2. Sirtuin3 (SIRT3)-mediated metabolic downstream events during myocardial ischemia and reperfusion (I/R).

On the other hand, Lombard et al. implicated that SIRT3 is the leader that controls mitochondrial deacetylation, since the significant hyperacetylation of a wide range of mitochondrial proteins was observed in SIRT3-deficient mice [32]. SIRT3 has the capacity to deacetylase complex I subunit NDUFA9 and complex II subunit SDHA in the mitochondria ETC and augment its activity to maintain the ATP level $[138,139]$ (Figure 2). The deletion of SIRT3 increased the sensitivity to I/R injury and showed increased ROS leakage out and a lowered level of cellular ATP $[20,140]$. These indicate that SIRT3 could maintain the redox and energy homeostasis through the direct deacetylation of mitochondria ETC complex members. Previous research demonstrated that SIRT3 deacetylates and triggers the enzyme activity of isocitrate dehydrogenase 2 (IDH2), which utilizes $\mathrm{NADP}^{+}$and produces NADPH in the TCA cycle during I/R (Figure 2). The deletion of IDH2 amplifies the liver susceptibility to $\mathrm{I} / \mathrm{R}$ injury, which is associated with more severe mitochondrial oxidative injury [141,142]. In turn, the upregulation of NADPH is essential for the ROS clearance by mitochondrial glutathione peroxidase (GPX) linked with the process of converting oxidized glutathione (GSSG) into glutathione (GSH). These data suggest that SIRT3 could increase the NADPH level via the deacetylation of IDH2, which increases the GSH and inhibits ROS formation during I/R. In addition, FoxO3, another member of the forkhead transcription factors family, controls cardiac metabolism [143], which is another target for SIRT3-mediated deacetylation [144] (Figure 2). It binds to the gene promoters of MnSOD and induces its transcriptional expression, thereby detoxifying the cellular ROS levels. It is notable that the SIRT3/FoxO3a/MnSOD signaling pathway also plays an important role during I/R in the heart $[145,146]$.

Moreover, macrophages isolated from SIRT3 knockout mice show significant changes in mitochondrial redox homeostasis, which are accompanied by pro-inflammatory-like phenotype 
alterations as a result of the activation of the NLRP3 inflammasome, as well as the NF- $\mathrm{KB}$ pathway [147]. These data implicate that SIRT3 may be involved in the regulation of the cytoplasmic ROS level. One study observed an unchanged phosphorylation at endothelial NOS (eNOS) Ser1177, which is replaced by a decreased phosphorylation of eNOS Thr495 following the transient deletion of SIRT3, which is equivalent to an increased enzymatic activity [148]. SIRT3 deficiency may cause a compensatory effect that is secondary to an increased mitochondrial ROS accumulation. Thus, the increased eNOS activity does not generate an increase in NO upon SIRT3 deficiency. However, the increased eNOS coupling may contribute to counteract increased ROS levels upon SIRT3 deficiency [148]. However, several questions still need to be addressed to fully understand the function of SIRT3 on cytoplasm ROS level upon myocardial I/R.

\section{Conclusions}

Taken together, the balance between the synthesis and clearance of ROS is crucial to maintain healthy homeostasis of the cardiomyocytes under both physiology and I/R stress. Aging markedly increased the damage induced by $\mathrm{I} / \mathrm{R}$ injury with more severe cardiac dysfunction and myocardial infarction due to the increased free radicals leading to more ROS generation. Age-related excessive ROS production during I/R injury plays a vital role in a series of cellular transductions that lead to mitochondria dysfunction and cardiomyocytes death and finally to severe organ injury.

SIRT1 and SIRT3 have been proposed to be aging-related proteins that mediate the response to I/R stress, especially in aging. Recent studies revealed that defect SIRT1 or SIRT3 increased the sensitivity of hearts to I/R stress as well as enhanced the cardiac ROS level, especially in aged individuals. These indicated that SIRT1 and SIRT3 have robust functions in modulating cardiac ROS production under I/R stress. Notably, ROS and SIRT1/SIRT3 are major regulators of substrate metabolism, which modulates the inflammatory responses during myocardial ischemia and reperfusion. Both metabolic and inflammatory homeostasis are disturbed in aging during the $\mathrm{I} / \mathrm{R}$ process. It seems that there is an optimal balance between the levels of ROS production and either metabolism or inflammation with the regulation of SIRT1/SIRT3, which confers the most favorable benefits on the protection of the aging heart from more severe I/R injury. Further studies should aim to determine the activity of SIRT1 and SIRT3 on enzyme alterations that drive ROS production in cardiomyocytes involved in the process of IR stress.

Previous findings revealed the discovery of one of the first sirtuin-activating compounds (STACs), resveratrol, via a screen for molecules. Resveratrol increases the activity of human SIRT1 and extends the lifespan of yeast [149]. In addition to SIRT1, resveratrol has been reported to activate SIRT3 and SIRT5, as well as other non-sirtuin targets [10]. After that, several generations of STACs with increasing potency and specificity are generated, including SRT1720 and SRT2104 [150]. STACs bind to the STAC-binding domain in the N terminus of SIRT1 and increase the binding affinity of a substrate for SIRT1 [151]. Honokiol is believed to be a specific SIRT3 activator, although it may also activate SIRT1 [16,152]. It is also necessary to implement the studies with cardiac-specific transgenic mice that inhibit the expression of SIRT1 and SIRT3 in combination with STACs in order to confirm the mechanisms of individual sirtuins. Those studies could contribute to improving the therapeutically effects in a clinical setting and provide appropriate therapeutic approaches for age-related ischemic disease.

Author Contributions: Writing—original draft preparation, J.Z.; writing—review and editing, J.Z., D.R., J.F., Z.H. and J.L.; supervision, J.L. All authors have read and agreed to the published version of the manuscript.

Funding: This research was funded by 2018 Overseas Doctoral Training Program and Graduate Mentor Visiting Program of Shandong Province, grant number 109115.

Conflicts of Interest: The authors declare no conflict of interest. 


\section{References}

1. Akhtar, S. Ischemic heart disease. Anesthesiol. Clin. 2006, 24, 461-485. [CrossRef]

2. Fan, Q.; Chen, M.; Fang, X.; Lau, W.B.; Xue, L.; Zhao, L.; Zhang, H.; Liang, Y.H.; Bai, X.; Niu, H.Y.; et al. Aging might augment reactive oxygen species (ROS) formation and affect reactive nitrogen species (RNS) level after myocardial ischemia/reperfusion in both humans and rats. Age (Dordr) 2013, 35, 1017-1026. [CrossRef] [PubMed]

3. Fridovich, I. Mitochondria: Are they the seat of senescence? Aging Cell 2004, 3, 13-16. [CrossRef] [PubMed]

4. Giorgi, C.; Marchi, S.; Simoes, I.C.M.; Ren, Z.; Morciano, G.; Perrone, M.; Patalas-Krawczyk, P.; Borchard, S.; Jędrak, P.; Pierzynowska, K.; et al. Mitochondria and Reactive Oxygen Species in Aging and Age-Related Diseases. Int. Rev. Cell Mol. Biol. 2018, 340, 209-344. [CrossRef] [PubMed]

5. Ortuno-Sahagun, D.; Pallas, M.; Rojas-Mayorquin, A.E. Oxidative stress in aging: Advances in proteomic approaches. Oxid. Med. Cell Longev. 2014, 2014, 573208. [CrossRef]

6. Cadenas, S. ROS and redox signaling in myocardial ischemia-reperfusion injury and cardioprotection. Free Radic. Biol. Med. 2018, 117, 76-89. [CrossRef] [PubMed]

7. Van de Ven, R.A.H.; Santos, D.; Haigis, M.C. Mitochondrial Sirtuins and Molecular Mechanisms of Aging. Trends Mol. Med. 2017, 23, 320-331. [CrossRef]

8. Imai, S.I.; Guarente, L. It takes two to tango: $\mathrm{NAD}(+)$ and sirtuins in aging/longevity control. NPJ Aging Mech. Dis. 2016, 2, 16017. [CrossRef]

9. Lagunas-Rangel, F.A. Current role of mammalian sirtuins in DNA repair. DNA Repair (Amst.) 2019, 80, 85-92. [CrossRef]

10. Kane, A.E.; Sinclair, D.A. Sirtuins and $\mathrm{NAD}(+)$ in the Development and Treatment of Metabolic and Cardiovascular Diseases. Circ. Res. 2018, 123, 868-885. [CrossRef]

11. Mendes, K.L.; Lelis, D.F.; Santos, S.H.S. Nuclear sirtuins and inflammatory signaling pathways. Cytokine Growth Factor Rev. 2017, 38, 98-105. [CrossRef] [PubMed]

12. Liu, Q.; Li, H.; Wang, J.; Zhong, L.; Chen, X.; Zhang, R.; Wang, H. Glucose restriction delays senescence and promotes proliferation of HUVECs via the AMPK/SIRT1-FOXA3-Beclin1 pathway. Exp. Gerontol. 2020, 111053. [CrossRef] [PubMed]

13. Jang, K.H.; Hwang, Y.; Kim, E. PARP1 Impedes SIRT1-Mediated Autophagy during Degeneration of the Retinal Pigment Epithelium under Oxidative Stress. Mol. Cells 2020, 43, 632-644. [CrossRef] [PubMed]

14. Hsu, C.P.; Zhai, P.; Yamamoto, T.; Maejima, Y.; Matsushima, S.; Hariharan, N.; Shao, D.; Takagi, H.; Oka, S.; Sadoshima, J. Silent information regulator 1 protects the heart from ischemia/reperfusion. Circulation 2010, 122, 2170-2182. [CrossRef] [PubMed]

15. Ye, L.; Li, M.; Wang, Z.; Yang, Z.; Zhang, J.; Fang, H.; He, Z.; Wang, X. Depression of Mitochondrial Function in the Rat Skeletal Muscle Model of Myofascial Pain Syndrome Is through Down-Regulation of the AMPK-PGC-1 $\alpha$-SIRT3 Axis. J. Pain Res. 2020, 13, 1747-1756. [CrossRef]

16. Caballero, E.P.; Mariz-Ponte, N.; Rigazio, C.S.; Santamaría, M.H.; Corral, R.S. Honokiol attenuates oxidative stress-dependent heart dysfunction in chronic Chagas disease by targeting AMPK/NFE2L2/SIRT3 signaling pathway. Free Radic. Biol. Med. 2020, 156, 113-124. [CrossRef]

17. Wang, C.H.; Wei, Y.H. Roles of Mitochondrial Sirtuins in Mitochondrial Function, Redox Homeostasis, Insulin Resistance and Type 2 Diabetes. Int. J. Mol. Sci. 2020, 21, 5266. [CrossRef]

18. Xin, T.; Lu, C. SirT3 activates AMPK-related mitochondrial biogenesis and ameliorates sepsis-induced myocardial injury. Aging (Albany NY) 2020, 12, 16224-16231. [CrossRef]

19. Parodi-Rullan, R.M.; Chapa-Dubocq, X.; Rullan, P.J.; Jang, S.; Javadov, S. High Sensitivity of SIRT3 Deficient Hearts to Ischemia-Reperfusion Is Associated with Mitochondrial Abnormalities. Front. Pharmacol. 2017, 8 , 275. [CrossRef]

20. Porter, G.A.; Urciuoli, W.R.; Brookes, P.S.; Nadtochiy, S.M. SIRT3 deficiency exacerbates ischemia-reperfusion injury: Implication for aged hearts. Am. J. Physiol. Heart Circ. Physiol. 2014, 306, H1602-H1609. [CrossRef]

21. Lavu, S.; Boss, O.; Elliott, P.J.; Lambert, P.D. Sirtuins-Novel therapeutic targets to treat age-associated diseases. Nat. Rev. Drug Discov. 2008, 7, 841-853. [CrossRef] [PubMed]

22. Verma, A.K.; Singh, S.; Rizvi, S.I. Age-dependent altered redox homeostasis in the chronodisrupted rat model and moderation by melatonin administration. Chronobiol. Int. 2020, 1-11. [CrossRef] [PubMed] 
23. Wang, T.; Wang, Y.; Liu, L.; Jiang, Z.; Li, X.; Tong, R.; He, J.; Shi, J. Research progress on sirtuins family members and cell senescence. Eur. J. Med. Chem. 2020, 193, 112207. [CrossRef] [PubMed]

24. Morris, B.J. Seven sirtuins for seven deadly diseases of aging. Free Radic. Biol. Med. 2013, 56, $133-171$. [CrossRef]

25. Haigis, M.C.; Mostoslavsky, R.; Haigis, K.M.; Fahie, K.; Christodoulou, D.C.; Murphy, A.J.; Valenzuela, D.M.; Yancopoulos, G.D.; Karow, M.; Blander, G.; et al. SIRT4 inhibits glutamate dehydrogenase and opposes the effects of calorie restriction in pancreatic beta cells. Cell 2006, 126, 941-954. [CrossRef]

26. Maurer, B.; Rumpf, T.; Scharfe, M.; Stolfa, D.A.; Schmitt, M.L.; He, W.; Verdin, E.; Sippl, W.; Jung, M. Inhibitors of the NAD(+)-Dependent Protein Desuccinylase and Demalonylase Sirt5. ACS Med. Chem. Lett. 2012, 3, 1050-1053. [CrossRef]

27. Du, J.; Zhou, Y.; Su, X.; Yu, J.J.; Khan, S.; Jiang, H.; Kim, J.; Woo, J.; Kim, J.H.; Choi, B.H.; et al. Sirt5 is a NAD-dependent protein lysine demalonylase and desuccinylase. Science 2011, 334, 806-809. [CrossRef]

28. Zhao, L.; Cao, J.; Hu, K.; He, X.; Yun, D.; Tong, T.; Han, L. Sirtuins and their Biological Relevance in Aging and Age-Related Diseases. Aging Dis. 2020, 11, 927-945. [CrossRef]

29. Kanfi, Y.; Naiman, S.; Amir, G.; Peshti, V.; Zinman, G.; Nahum, L.; Bar-Joseph, Z.; Cohen, H.Y. The sirtuin SIRT6 regulates lifespan in male mice. Nature 2012, 483, 218-221. [CrossRef]

30. Cheng, H.L.; Mostoslavsky, R.; Saito, S.; Manis, J.P.; Gu, Y.; Patel, P.; Bronson, R.; Appella, E.; Alt, F.W.; Chua, K.F. Developmental defects and p53 hyperacetylation in Sir2 homolog (SIRT1)-deficient mice. Proc. Natl. Acad. Sci. USA 2003, 100, 10794-10799. [CrossRef]

31. Satoh, A.; Brace, C.S.; Rensing, N.; Cliften, P.; Wozniak, D.F.; Herzog, E.D.; Yamada, K.A.; Imai, S. Sirt1 extends life span and delays aging in mice through the regulation of Nk2 homeobox 1 in the DMH and LH. Cell Metab. 2013, 18, 416-430. [CrossRef] [PubMed]

32. Lombard, D.B.; Alt, F.W.; Cheng, H.L.; Bunkenborg, J.; Streeper, R.S.; Mostoslavsky, R.; Kim, J.; Yancopoulos, G.; Valenzuela, D.; Murphy, A.; et al. Mammalian Sir2 homolog SIRT3 regulates global mitochondrial lysine acetylation. Mol. Cell Biol. 2007, 27, 8807-8814. [CrossRef] [PubMed]

33. Bellizzi, D.; Dato, S.; Cavalcante, P.; Covello, G.; Di Cianni, F.; Passarino, G.; Rose, G.; De Benedictis, G. Characterization of a bidirectional promoter shared between two human genes related to aging: SIRT3 and PSMD13. Genomics 2007, 89, 143-150. [CrossRef] [PubMed]

34. Bellizzi, D.; Rose, G.; Cavalcante, P.; Covello, G.; Dato, S.; De Rango, F.; Greco, V.; Maggiolini, M.; Feraco, E.; Mari, V.; et al. A novel VNTR enhancer within the SIRT3 gene, a human homologue of SIR2, is associated with survival at oldest ages. Genomics 2005, 85, 258-263. [CrossRef] [PubMed]

35. Brown, K.; Xie, S.; Qiu, X.; Mohrin, M.; Shin, J.; Liu, Y.; Zhang, D.; Scadden, D.T.; Chen, D. SIRT3 reverses aging-associated degeneration. Cell Rep. 2013, 3, 319-327. [CrossRef]

36. Wang, L.; Quan, N.; Sun, W.; Chen, X.; Cates, C.; Rousselle, T.; Zhou, X.; Zhao, X.; Li, J. Cardiomyocyte-specific deletion of Sirt1 gene sensitizes myocardium to ischaemia and reperfusion injury. Cardiovasc. Res. 2018, 114, 805-821. [CrossRef] [PubMed]

37. Han, Y.; Sun, W.; Ren, D.; Zhang, J.; He, Z.; Fedorova, J.; Sun, X.; Han, F.; Li, J. SIRT1 agonism modulates cardiac NLRP3 inflammasome through pyruvate dehydrogenase during ischemia and reperfusion. Redox Biol. 2020, 34, 101538. [CrossRef]

38. Han, D.; Wang, J.; Ma, S.; Chen, Y.; Cao, F. SIRT1 as a Promising Novel Therapeutic Target for Myocardial Ischemia Reperfusion Injury and Cardiometabolic Disease. Curr. Drug Targets 2017, 18, 1746-1753. [CrossRef]

39. Alcendor, R.R.; Kirshenbaum, L.A.; Imai, S.; Vatner, S.F.; Sadoshima, J. Silent information regulator 2alpha, a longevity factor and class III histone deacetylase, is an essential endogenous apoptosis inhibitor in cardiac myocytes. Circ. Res. 2004, 95, 971-980. [CrossRef]

40. Carrico, C.; Meyer, J.G.; He, W.; Gibson, B.W.; Verdin, E. The Mitochondrial Acylome Emerges: Proteomics, Regulation by Sirtuins, and Metabolic and Disease Implications. Cell Metab. 2018, 27, 497-512. [CrossRef]

41. Zheng, Y.; Shi, B.; Ma, M.; Wu, X.; Lin, X. The novel relationship between Sirt3 and autophagy in myocardial ischemia-reperfusion. J. Cell Physiol. 2019, 234, 5488-5495. [CrossRef] [PubMed]

42. Yu, W.; Gao, B.; Li, N.; Wang, J.; Qiu, C.; Zhang, G.; Liu, M.; Zhang, R.; Li, C.; Ji, G.; et al. Sirt3 deficiency exacerbates diabetic cardiac dysfunction: Role of Foxo3A-Parkin-mediated mitophagy. Biochim. Biophys. Acta Mol. Basis Dis. 2017, 1863, 1973-1983. [CrossRef] [PubMed]

43. Young, I.S.; Woodside, J.V. Antioxidants in health and disease. J. Clin. Pathol. 2001, 54, 176-186. [CrossRef] 
44. Burgoyne, J.R.; Mongue-Din, H.; Eaton, P.; Shah, A.M. Redox signaling in cardiac physiology and pathology. Circ. Res. 2012, 111, 1091-1106. [CrossRef] [PubMed]

45. Chen, Y.R.; Zweier, J.L. Cardiac mitochondria and reactive oxygen species generation. Circ. Res. 2014, 114, 524-537. [CrossRef]

46. Hausenloy, D.J.; Yellon, D.M. Myocardial ischemia-reperfusion injury: A neglected therapeutic target. J. Clin. Investig. 2013, 123, 92-100. [CrossRef]

47. Lenaz, G. Mitochondria and reactive oxygen species. Which role in physiology and pathology? Adv. Exp. Med. Biol. 2012, 942, 93-136. [CrossRef]

48. Forrester, S.J.; Kikuchi, D.S.; Hernandes, M.S.; Xu, Q.; Griendling, K.K. Reactive Oxygen Species in Metabolic and Inflammatory Signaling. Circ. Res. 2018, 122, 877-902. [CrossRef]

49. Zhao, R.Z.; Jiang, S.; Zhang, L.; Yu, Z.B. Mitochondrial electron transport chain, ROS generation and uncoupling (Review). Int. J. Mol. Med. 2019, 44, 3-15. [CrossRef]

50. Sazanov, L.A.; Hinchliffe, P. Structure of the hydrophilic domain of respiratory complex I from Thermus thermophilus. Science 2006, 311, 1430-1436. [CrossRef]

51. Lambert, A.J.; Buckingham, J.A.; Boysen, H.M.; Brand, M.D. Diphenyleneiodonium acutely inhibits reactive oxygen species production by mitochondrial complex I during reverse, but not forward electron transport. Biochim. Biophys. Acta 2008, 1777, 397-403. [CrossRef] [PubMed]

52. Pryde, K.R.; Hirst, J. Superoxide is produced by the reduced flavin in mitochondrial complex I: A single, unified mechanism that applies during both forward and reverse electron transfer. J. Biol. Chem. 2011, 286, 18056-18065. [CrossRef] [PubMed]

53. St-Pierre, J.; Buckingham, J.A.; Roebuck, S.J.; Brand, M.D. Topology of superoxide production from different sites in the mitochondrial electron transport chain. J. Biol. Chem. 2002, 277, 44784-44790. [CrossRef] [PubMed]

54. Miwa, S.; St-Pierre, J.; Partridge, L.; Brand, M.D. Superoxide and hydrogen peroxide production by Drosophila mitochondria. Free Radic. Biol. Med. 2003, 35, 938-948. [CrossRef]

55. Miwa, S.; Brand, M.D. The topology of superoxide production by complex III and glycerol 3-phosphate dehydrogenase in Drosophila mitochondria. Biochim. Biophys. Acta 2005, 1709, 214-219. [CrossRef]

56. Turrens, J.F.; Alexandre, A.; Lehninger, A.L. Ubisemiquinone is the electron donor for superoxide formation by complex III of heart mitochondria. Arch. Biochem. Biophys. 1985, 237, 408-414. [CrossRef]

57. Kundu, A.; Vaze, A.; Sardar, P.; Nagy, A.; Aronow, W.S.; Botkin, N.F. Variant Angina and Aborted Sudden Cardiac Death. Curr. Cardiol. Rep. 2018, 20, 26. [CrossRef]

58. Morrison, A.; Li, J. PPAR-gamma and AMPK-advantageous targets for myocardial ischemia/reperfusion therapy. Biochem. Pharmacol. 2011, 82, 195-200. [CrossRef]

59. Costa, R.; Morrison, A.; Wang, J.; Manithody, C.; Li, J.; Rezaie, A.R. Activated protein C modulates cardiac metabolism and augments autophagy in the ischemic heart. J. Thromb. Haemost. 2012, 10, 1736-1744. [CrossRef]

60. Li, X.; Augustine, A.; Sun, D.; Li, L.; Fliegel, L. Activation of the $\mathrm{Na}(+) / \mathrm{H}(+)$ exchanger in isolated cardiomyocytes through beta-Raf dependent pathways. Role of Thr(653) of the cytosolic tail. J. Mol. Cell. Cardiol. 2016, 99, 65-75. [CrossRef]

61. Yokoyama, H.; Gunasegaram, S.; Harding, S.E.; Avkiran, M. Sarcolemmal Na+/H+ exchanger activity and expression in human ventricular myocardium. J. Am. Coll. Cardiol. 2000, 36, 534-540. [CrossRef]

62. Zhou, T.; Chuang, C.C.; Zuo, L. Molecular Characterization of Reactive Oxygen Species in Myocardial Ischemia-Reperfusion Injury. Biomed. Res. Int. 2015, 2015, 864946. [CrossRef]

63. Zhu, X.; Zuo, L. Characterization of oxygen radical formation mechanism at early cardiac ischemia. Cell Death Dis. 2013, 4, e787. [CrossRef] [PubMed]

64. Paradies, G.; Petrosillo, G.; Pistolese, M.; Di Venosa, N.; Federici, A.; Ruggiero, F.M. Decrease in mitochondrial complex I activity in ischemic/reperfused rat heart: Involvement of reactive oxygen species and cardiolipin. Circ. Res. 2004, 94, 53-59. [CrossRef] [PubMed]

65. Chen, Q.; Vazquez, E.J.; Moghaddas, S.; Hoppel, C.L.; Lesnefsky, E.J. Production of reactive oxygen species by mitochondria: Central role of complex III. J. Biol. Chem. 2003, 278, 36027-36031. [CrossRef]

66. Inserte, J.; Hernando, V.; Garcia-Dorado, D. Contribution of calpains to myocardial ischaemia/reperfusion injury. Cardiovasc. Res. 2012, 96, 23-31. [CrossRef] 
67. Wu, M.Y.; Yiang, G.T.; Liao, W.T.; Tsai, A.P.; Cheng, Y.L.; Cheng, P.W.; Li, C.Y.; Li, C.J. Current Mechanistic Concepts in Ischemia and Reperfusion Injury. Cell Physiol. Biochem. 2018, 46, 1650-1667. [CrossRef]

68. Turgeon, R.D.; Pearson, G.J.; Graham, M.M. Pharmacologic Treatment of Patients with Myocardial Ischemia With No Obstructive Coronary Artery Disease. Am. J. Cardiol. 2018, 121, 888-895. [CrossRef]

69. Bulluck, H.; Yellon, D.M.; Hausenloy, D.J. Reducing myocardial infarct size: Challenges and future opportunities. Heart 2016, 102, 341-348. [CrossRef]

70. Davidson, S.M.; Ferdinandy, P.; Andreadou, I.; Botker, H.E.; Heusch, G.; Ibanez, B.; Ovize, M.; Schulz, R.; Yellon, D.M.; Hausenloy, D.J.; et al. Multitarget Strategies to Reduce Myocardial Ischemia/Reperfusion Injury: JACC Review Topic of the Week. J. Am. Coll. Cardiol. 2019, 73, 89-99. [CrossRef]

71. Dhalla, N.S.; Elmoselhi, A.B.; Hata, T.; Makino, N. Status of myocardial antioxidants in ischemia-reperfusion injury. Cardiovasc. Res. 2000, 47, 446-456. [CrossRef]

72. Pei, H.; Yang, Y.; Zhao, H.; Li, X.; Yang, D.; Li, D. The Role of Mitochondrial Functional Proteins in ROS Production in Ischemic Heart Diseases. Oxid. Med. Cell. Longev. 2016, 2016, 5470457. [CrossRef] [PubMed]

73. Chouchani, E.T.; Pell, V.R.; James, A.M.; Work, L.M.; Saeb-Parsy, K.; Frezza, C.; Krieg, T.; Murphy, M.P. A Unifying Mechanism for Mitochondrial Superoxide Production during Ischemia-Reperfusion Injury. Cell Metab. 2016, 23, 254-263. [CrossRef] [PubMed]

74. Chouchani, E.T.; Pell, V.R.; Gaude, E.; Aksentijevic, D.; Sundier, S.Y.; Robb, E.L.; Logan, A.; Nadtochiy, S.M.; Ord, E.N.J.; Smith, A.C.; et al. Ischaemic accumulation of succinate controls reperfusion injury through mitochondrial ROS. Nature 2014, 515, 431-435. [CrossRef] [PubMed]

75. Andrienko, T.N.; Pasdois, P.; Pereira, G.C.; Ovens, M.J.; Halestrap, A.P. The role of succinate and ROS in reperfusion injury-A critical appraisal. J. Mol. Cell. Cardiol. 2017, 110, 1-14. [CrossRef] [PubMed]

76. Solaini, G.; Harris, D.A. Biochemical dysfunction in heart mitochondria exposed to ischaemia and reperfusion. Biochem. J. 2005, 390, 377-394. [CrossRef]

77. Ma, Y.; Li, J. Metabolic shifts during aging and pathology. Compr. Physiol. 2015, 5, 667-686. [CrossRef]

78. Favero, G.; Franceschetti, L.; Buffoli, B.; Moghadasian, M.H.; Reiter, R.J.; Rodella, L.F.; Rezzani, R. Melatonin: Protection against age-related cardiac pathology. Ageing Res. Rev. 2017, 35, 336-349. [CrossRef]

79. Gates, P.E.; Tanaka, H.; Graves, J.; Seals, D.R. Left ventricular structure and diastolic function with human ageing. Relation to habitual exercise and arterial stiffness. Eur. Heart J. 2003, 24, 2213-2220. [CrossRef]

80. Arieli, Y.; Gursahani, H.; Eaton, M.M.; Hernandez, L.A.; Schaefer, S. Gender modulation of Ca(2+) uptake in cardiac mitochondria. J. Mol. Cell. Cardiol. 2004, 37, 507-513. [CrossRef]

81. Adler, A.; Messina, E.; Sherman, B.; Wang, Z.; Huang, H.; Linke, A.; Hintze, T.H. NAD(P)H oxidase-generated superoxide anion accounts for reduced control of myocardial $\mathrm{O}_{2}$ consumption by NO in old Fischer 344 rats. Am. J. Physiol. Heart Circ. Physiol. 2003, 285, H1015-H1022. [CrossRef] [PubMed]

82. Wojtovich, A.P.; Nadtochiy, S.M.; Brookes, P.S.; Nehrke, K. Ischemic preconditioning: The role of mitochondria and aging. Exp. Gerontol. 2012, 47, 1-7. [CrossRef] [PubMed]

83. Ma, H.; Wang, J.; Thomas, D.P.; Tong, C.; Leng, L.; Wang, W.; Merk, M.; Zierow, S.; Bernhagen, J.; Ren, J.; et al. Impaired macrophage migration inhibitory factor-AMP-activated protein kinase activation and ischemic recovery in the senescent heart. Circulation 2010, 122, 282-292. [CrossRef] [PubMed]

84. Quan, N.; Sun, W.; Wang, L.; Chen, X.; Bogan, J.S.; Zhou, X.; Cates, C.; Liu, Q.; Zheng, Y.; Li, J. Sestrin2 prevents age-related intolerance to ischemia and reperfusion injury by modulating substrate metabolism. FASEB J. 2017, 31, 4153-4167. [CrossRef]

85. Harman, D. Free radical theory of aging: An update: Increasing the functional life span. Ann. N. Y. Acad. Sci. 2006, 1067, 10-21. [CrossRef] [PubMed]

86. Luo, J.; Mills, K.; le Cessie, S.; Noordam, R.; van Heemst, D. Ageing, age-related diseases and oxidative stress: What to do next? Ageing Res. Rev. 2020, 57, 100982. [CrossRef]

87. Thoma, A.; Akter-Miah, T.; Reade, R.L.; Lightfoot, A.P. Targeting reactive oxygen species (ROS) to combat the age-related loss of muscle mass and function. Biogerontology 2020, 21, 475-484. [CrossRef]

88. de Almeida, A.J.P.O.; de Almeida Rezende, M.S.; Dantas, S.H.; de Lima Silva, S.; de Oliveira, J.C.P.L.; de Lourdes Assunção Araújo de Azevedo, F.; Alves, R.M.F.R.; de Menezes, G.M.S.; Dos Santos, P.F.; Gonçalves, T.A.F.; et al. Unveiling the Role of Inflammation and Oxidative Stress on Age-Related Cardiovascular Diseases. Oxid. Med. Cell. Longev. 2020, 2020, 1954398. [CrossRef]

89. Boengler, K.; Schulz, R.; Heusch, G. Loss of cardioprotection with ageing. Cardiovasc. Res. 2009, 83, $247-261$. [CrossRef] 
90. Escobales, N.; Nuñez, R.E.; Jang, S.; Parodi-Rullan, R.; Ayala-Peña, S.; Sacher, J.R.; Skoda, E.M.; Wipf, P.; Frontera, W.; Javadov, S. Mitochondria-targeted ROS scavenger improves post-ischemic recovery of cardiac function and attenuates mitochondrial abnormalities in aged rats. J. Mol. Cell. Cardiol. 2014, 77, 136-146. [CrossRef]

91. Lesnefsky, E.J.; Hoppel, C.L. Ischemia-reperfusion injury in the aged heart: Role of mitochondria. Arch. Biochem. Biophys. 2003, 420, 287-297. [CrossRef] [PubMed]

92. Tocchi, A.; Quarles, E.K.; Basisty, N.; Gitari, L.; Rabinovitch, P.S. Mitochondrial dysfunction in cardiac aging. Biochim. Biophys. Acta 2015, 1847, 1424-1433. [CrossRef] [PubMed]

93. Lesnefsky, E.J.; Chen, Q.; Hoppel, C.L. Mitochondrial Metabolism in Aging Heart. Circ. Res. 2016, 118, 1593-1611. [CrossRef] [PubMed]

94. Kelm, N.Q.; Beare, J.E.; Weber, G.J.; LeBlanc, A.J. Thrombospondin-1 mediates Drp-1 signaling following ischemia reperfusion in the aging heart. FASEB Bioadv. 2020, 2, 304-314. [CrossRef] [PubMed]

95. Frangogiannis, N.G. The inflammatory response in myocardial injury, repair, and remodelling. Nat. Rev. Cardiol. 2014, 11, 255-265. [CrossRef]

96. Fukushima, A.; Lopaschuk, G.D. Acetylation control of cardiac fatty acid $\beta$-oxidation and energy metabolism in obesity, diabetes, and heart failure. Biochim. Biophys. Acta 2016, 1862, 2211-2220. [CrossRef]

97. Guarente, L. Sirtuins in aging and disease. Cold Spring Harb. Symp. Quant Biol. 2007, 72, 483-488. [CrossRef]

98. Tong, C.; Morrison, A.; Mattison, S.; Qian, S.; Bryniarski, M.; Rankin, B.; Wang, J.; Thomas, D.P.; Li, J. Impaired SIRT1 nucleocytoplasmic shuttling in the senescent heart during ischemic stress. FASEB J. 2013, 27, 4332-4342. [CrossRef]

99. Kwon, S.; Seok, S.; Yau, P.; Li, X.; Kemper, B.; Kemper, J.K. Obesity and aging diminish sirtuin 1 (SIRT1)-mediated deacetylation of SIRT3, leading to hyperacetylation and decreased activity and stability of SIRT3. J. Biol. Chem. 2017, 292, 17312-17323. [CrossRef]

100. Alcendor, R.R.; Gao, S.; Zhai, P.; Zablocki, D.; Holle, E.; Yu, X.; Tian, B.; Wagner, T.; Vatner, S.F.; Sadoshima, J. Sirt1 regulates aging and resistance to oxidative stress in the heart. Circ. Res. 2007, 100, 1512-1521. [CrossRef]

101. Winnik, S.; Auwerx, J.; Sinclair, D.A.; Matter, C.M. Protective effects of sirtuins in cardiovascular diseases: From bench to bedside. Eur. Heart J. 2015, 36, 3404-3412. [CrossRef] [PubMed]

102. Planavila, A.; Iglesias, R.; Giralt, M.; Villarroya, F. Sirt1 acts in association with PPARalpha to protect the heart from hypertrophy, metabolic dysregulation, and inflammation. Cardiovasc. Res. 2011, 90, $276-284$. [CrossRef] [PubMed]

103. Gu, C.; Xing, Y.; Jiang, L.; Chen, M.; Xu, M.; Yin, Y.; Li, C.; Yang, Z.; Yu, L.; Ma, H. Impaired cardiac SIRT1 activity by carbonyl stress contributes to aging-related ischemic intolerance. PLoS ONE 2013, 8, e74050. [CrossRef]

104. Nemoto, S.; Fergusson, M.M.; Finkel, T. SIRT1 functionally interacts with the metabolic regulator and transcriptional coactivator PGC-1\{alpha\}. J. Biol. Chem. 2005, 280, 16456-16460. [CrossRef] [PubMed]

105. Tang, B.L. Sirt1 and the Mitochondria. Mol. Cells 2016, 39, 87-95. [CrossRef] [PubMed]

106. Scarpulla, R.C. Metabolic control of mitochondrial biogenesis through the PGC-1 family regulatory network. Biochim. Biophys. Acta 2011, 1813, 1269-1278. [CrossRef] [PubMed]

107. Li, X.; Liu, Y.; Ma, H.; Guan, Y.; Cao, Y.; Tian, Y.; Zhang, Y. Enhancement of Glucose Metabolism via PGC-1alpha Participates in the Cardioprotection of Chronic Intermittent Hypobaric Hypoxia. Front. Physiol. 2016, 7, 219. [CrossRef]

108. Lehman, J.J.; Boudina, S.; Banke, N.H.; Sambandam, N.; Han, X.; Young, D.M.; Leone, T.C.; Gross, R.W.; Lewandowski, E.D.; Abel, E.D.; et al. The transcriptional coactivator PGC-1alpha is essential for maximal and efficient cardiac mitochondrial fatty acid oxidation and lipid homeostasis. Am. J. Physiol. Heart Circ. Physiol. 2008, 295, H185-H196. [CrossRef]

109. Hosaka, T.; Biggs, W.H.; Tieu, D.; Boyer, A.D.; Varki, N.M.; Cavenee, W.K.; Arden, K.C. Disruption of forkhead transcription factor (FOXO) family members in mice reveals their functional diversification. Proc. Natl. Acad. Sci. USA 2004, 101, 2975-2980. [CrossRef]

110. Puthanveetil, P.; Wan, A.; Rodrigues, B. FoxO1 is crucial for sustaining cardiomyocyte metabolism and cell survival. Cardiovasc. Res. 2013, 97, 393-403. [CrossRef] 
111. Guan, X.H.; Liu, X.H.; Hong, X.; Zhao, N.; Xiao, Y.F.; Wang, L.F.; Tang, L.; Jiang, K.; Qian, Y.S.; Deng, K.Y.; et al. CD38 Deficiency Protects the Heart from Ischemia/Reperfusion Injury through Activating SIRT1/FOXOs-Mediated Antioxidative Stress Pathway. Oxid. Med. Cell Longev. 2016, 2016, 7410257. [CrossRef] [PubMed]

112. Wang, Y.H.; Li, S.A.; Huang, C.H.; Su, H.H.; Chen, Y.H.; Chang, J.T.; Huang, S.S. Sirt1 Activation by Post-ischemic Treatment With Lumbrokinase Protects against Myocardial Ischemia-Reperfusion Injury. Front. Pharmacol. 2018, 9, 636. [CrossRef] [PubMed]

113. Yang, J.; Marden, J.J.; Fan, C.; Sanlioglu, S.; Weiss, R.M.; Ritchie, T.C.; Davisson, R.L.; Engelhardt, J.F. Genetic redox preconditioning differentially modulates AP-1 and NF kappa B responses following cardiac ischemia/reperfusion injury and protects against necrosis and apoptosis. Mol. Ther. 2003, 7, 341-353. [CrossRef]

114. Sumimoto, H. Structure, regulation and evolution of Nox-family NADPH oxidases that produce reactive oxygen species. FEBS J. 2008, 275, 3249-3277. [CrossRef] [PubMed]

115. Anrather, J.; Racchumi, G.; Iadecola, C. NF-kappaB regulates phagocytic NADPH oxidase by inducing the expression of gp91phox. J. Biol. Chem. 2006, 281, 5657-5667. [CrossRef]

116. Manea, A.; Manea, S.A.; Gafencu, A.V.; Raicu, M. Regulation of NADPH oxidase subunit p22(phox) by NF-kB in human aortic smooth muscle cells. Arch. Physiol. Biochem. 2007, 113, 163-172. [CrossRef]

117. Yang, H.; Zhang, W.; Pan, H.; Feldser, H.G.; Lainez, E.; Miller, C.; Leung, S.; Zhong, Z.; Zhao, H.; Sweitzer, S.; et al. SIRT1 activators suppress inflammatory responses through promotion of p65 deacetylation and inhibition of NF-kappaB activity. PLoS ONE 2012, 7, e46364. [CrossRef]

118. Li, C.; Browder, W.; Kao, R.L. Early activation of transcription factor NF-kappaB during ischemia in perfused rat heart. Am. J. Physiol. 1999, 276, H543-H552. [CrossRef]

119. Li, D.; Wang, X.; Huang, Q.; Li, S.; Zhou, Y.; Li, Z. Cardioprotection of CAPE-oNO2 against myocardial ischemia/reperfusion induced ROS generation via regulating the SIRT1/eNOS/NF-kappaB pathway in vivo and in vitro. Redox Biol. 2018, 15, 62-73. [CrossRef]

120. Thiemermann, $C$. Inhibition of the activation of nuclear factor kappa B to reduce myocardial reperfusion injury and infarct size. Cardiovasc. Res. 2004, 63, 8-10. [CrossRef]

121. Guo, Z.; Shao, L.; Du, Q.; Park, K.S.; Geller, D.A. Identification of a classic cytokine-induced enhancer upstream in the human iNOS promoter. FASEB J. 2007, 21, 535-542. [CrossRef] [PubMed]

122. Helenius, M.; Kyrylenko, S.; Vehvilainen, P.; Salminen, A. Characterization of aging-associated up-regulation of constitutive nuclear factor-kappa B binding activity. Antioxid. Redox Signal. 2001, 3, 147-156. [CrossRef] [PubMed]

123. Helenius, M.; Hänninen, M.; Lehtinen, S.K.; Salminen, A. Aging-induced up-regulation of nuclear binding activities of oxidative stress responsive NF-kB transcription factor in mouse cardiac muscle. J. Mol. Cell Cardiol. 1996, 28, 487-498. [CrossRef] [PubMed]

124. Qiu, X.; Brown, K.; Hirschey, M.D.; Verdin, E.; Chen, D. Calorie restriction reduces oxidative stress by SIRT3-mediated SOD2 activation. Cell Metab. 2010, 12, 662-667. [CrossRef] [PubMed]

125. Pillai, V.B.; Sundaresan, N.R.; Kim, G.; Gupta, M.; Rajamohan, S.B.; Pillai, J.B.; Samant, S.; Ravindra, P.V.; Isbatan, A.; Gupta, M.P. Exogenous NAD blocks cardiac hypertrophic response via activation of the SIRT3-LKB1-AMP-activated kinase pathway. J. Biol. Chem. 2010, 285, 3133-3144. [CrossRef]

126. Chen, T.; Liu, J.; Li, N.; Wang, S.; Liu, H.; Li, J.; Zhang, Y.; Bu, P. Mouse SIRT3 attenuates hypertrophy-related lipid accumulation in the heart through the deacetylation of LCAD. PLoS ONE 2015, 10, e0118909. [CrossRef]

127. Lanza, I.R.; Short, D.K.; Short, K.R.; Raghavakaimal, S.; Basu, R.; Joyner, M.J.; McConnell, J.P.; Nair, K.S. Endurance exercise as a countermeasure for aging. Diabetes 2008, 57, 2933-2942. [CrossRef]

128. Sun, W.; Liu, C.; Chen, Q.; Liu, N.; Yan, Y.; Liu, B. SIRT3: A New Regulator of Cardiovascular Diseases. Oxid. Med. Cell Longev. 2018, 2018, 7293861. [CrossRef]

129. Jing, E.; O’Neill, B.T.; Rardin, M.J.; Kleinridders, A.; Ilkeyeva, O.R.; Ussar, S.; Bain, J.R.; Lee, K.Y.; Verdin, E.M.; Newgard, C.B.; et al. Sirt3 regulates metabolic flexibility of skeletal muscle through reversible enzymatic deacetylation. Diabetes 2013, 62, 3404-3417. [CrossRef]

130. Abo Alrob, O.; Lopaschuk, G.D. Role of CoA and acetyl-CoA in regulating cardiac fatty acid and glucose oxidation. Biochem. Soc. Trans. 2014, 42, 1043-1051. [CrossRef] 
131. Zhang, X.; Ji, R.; Liao, X.; Castillero, E.; Kennel, P.J.; Brunjes, D.L.; Franz, M.; Mobius-Winkler, S.; Drosatos, K.; George, I.; et al. MicroRNA-195 Regulates Metabolism in Failing Myocardium via Alterations in Sirtuin 3 Expression and Mitochondrial Protein Acetylation. Circulation 2018, 137, 2052-2067. [CrossRef] [PubMed]

132. Liemburg-Apers, D.C.; Willems, P.H.; Koopman, W.J.; Grefte, S. Interactions between mitochondrial reactive oxygen species and cellular glucose metabolism. Arch. Toxicol. 2015, 89, 1209-1226. [CrossRef] [PubMed]

133. Ozden, O.; Park, S.H.; Wagner, B.A.; Song, H.Y.; Zhu, Y.; Vassilopoulos, A.; Jung, B.; Buettner, G.R.; Gius, D. SIRT3 deacetylates and increases pyruvate dehydrogenase activity in cancer cells. Free Radic. Biol. Med. 2014, 76, 163-172. [CrossRef] [PubMed]

134. Patel, T.B.; Olson, M.S. Regulation of pyruvate dehydrogenase complex in ischemic rat heart. Am. J. Physiol. 1984, 246, H858-H864. [CrossRef] [PubMed]

135. Piao, L.; Fang, Y.H.; Kubler, M.M.; Donnino, M.W.; Sharp, W.W. Enhanced pyruvate dehydrogenase activity improves cardiac outcomes in a murine model of cardiac arrest. PLoS ONE 2017, 12, e0185046. [CrossRef]

136. Lewandowski, E.D.; White, L.T. Pyruvate dehydrogenase influences postischemic heart function. Circulation 1995, 91, 2071-2079. [CrossRef] [PubMed]

137. Fisher-Wellman, K.H.; Draper, J.A.; Davidson, M.T.; Williams, A.S.; Narowski, T.M.; Slentz, D.H.; Ilkayeva, O.R.; Stevens, R.D.; Wagner, G.R.; Najjar, R.; et al. Respiratory Phenomics across Multiple Models of Protein Hyperacylation in Cardiac Mitochondria Reveals a Marginal Impact on Bioenergetics. Cell Rep. 2019, 26, 1557-1572.e8. [CrossRef]

138. Ahn, B.H.; Kim, H.S.; Song, S.; Lee, I.H.; Liu, J.; Vassilopoulos, A.; Deng, C.X.; Finkel, T. A role for the mitochondrial deacetylase Sirt3 in regulating energy homeostasis. Proc. Natl. Acad. Sci. USA 2008, 105, 14447-14452. [CrossRef]

139. Cimen, H.; Han, M.J.; Yang, Y.; Tong, Q.; Koc, H.; Koc, E.C. Regulation of succinate dehydrogenase activity by SIRT3 in mammalian mitochondria. Biochemistry 2010, 49, 304-311. [CrossRef]

140. He, W.; Newman, J.C.; Wang, M.Z.; Ho, L.; Verdin, E. Mitochondrial sirtuins: Regulators of protein acylation and metabolism. Trends Endocrinol. Metab. 2012, 23, 467-476. [CrossRef]

141. Yu, W.; Dittenhafer-Reed, K.E.; Denu, J.M. SIRT3 protein deacetylates isocitrate dehydrogenase 2 (IDH2) and regulates mitochondrial redox status. J. Biol. Chem. 2012, 287, 14078-14086. [CrossRef]

142. Ku, H.J.; Ahn, Y.; Lee, J.H.; Park, K.M.; Park, J.W. IDH2 deficiency promotes mitochondrial dysfunction and cardiac hypertrophy in mice. Free Radic. Biol. Med. 2015, 80, 84-92. [CrossRef] [PubMed]

143. Tremblay, M.L.; Giguere, V. Phosphatases at the heart of FoxO metabolic control. Cell Metab. 2008, 7, $101-103$. [CrossRef] [PubMed]

144. Tseng, A.H.; Shieh, S.S.; Wang, D.L. SIRT3 deacetylates FOXO3 to protect mitochondria against oxidative damage. Free Radic. Biol. Med. 2013, 63, 222-234. [CrossRef] [PubMed]

145. Sundaresan, N.R.; Gupta, M.; Kim, G.; Rajamohan, S.B.; Isbatan, A.; Gupta, M.P. Sirt3 blocks the cardiac hypertrophic response by augmenting Foxo3a-dependent antioxidant defense mechanisms in mice. J. Clin. Investig. 2009, 119, 2758-2771. [CrossRef] [PubMed]

146. Chang, G.; Chen, Y.; Zhang, H.; Zhou, W. Trans sodium crocetinate alleviates ischemia/reperfusion-induced myocardial oxidative stress and apoptosis via the SIRT3/FOXO3a/SOD2 signaling pathway. Int. Immunopharmacol. 2019, 71,361-371. [CrossRef]

147. Kurundkar, D.; Kurundkar, A.R.; Bone, N.B.; Becker, E.J., Jr.; Liu, W.; Chacko, B.; Darley-Usmar, V.; Zmijewski, J.W.; Thannickal, V.J. SIRT3 diminishes inflammation and mitigates endotoxin-induced acute lung injury. JCI Insight 2019, 4, e120722. [CrossRef]

148. Winnik, S.; Gaul, D.S.; Siciliani, G.; Lohmann, C.; Pasterk, L.; Calatayud, N.; Weber, J.; Eriksson, U.; Auwerx, J.; van Tits, L.J.; et al. Mild endothelial dysfunction in Sirt3 knockout mice fed a high-cholesterol diet: Protective role of a novel C/EBP- $\beta$-dependent feedback regulation of SOD2. Basic Res. Cardiol. 2016, 111, 33. [CrossRef] [PubMed]

149. Hubbard, B.P.; Sinclair, D.A. Small molecule SIRT1 activators for the treatment of aging and age-related diseases. Trends Pharmacol. Sci. 2014, 35, 146-154. [CrossRef]

150. Schultz, M.B.; Rinaldi, C.; Lu, Y.; Amorim, J.A.; Sinclair, D.A. Molecular and Cellular Characterization of SIRT1 Allosteric Activators. Methods Mol. Biol. 2019, 1983, 133-149. [CrossRef] 
151. Dai, H.; Case, A.W.; Riera, T.V.; Considine, T.; Lee, J.E.; Hamuro, Y.; Zhao, H.; Jiang, Y.; Sweitzer, S.M.; Pietrak, B.; et al. Crystallographic structure of a small molecule SIRT1 activator-enzyme complex. Nat. Commun. 2015, 6, 7645. [CrossRef] [PubMed]

152. Pillai, V.B.; Samant, S.; Sundaresan, N.R.; Raghuraman, H.; Kim, G.; Bonner, M.Y.; Arbiser, J.L.; Walker, D.I.; Jones, D.P.; Gius, D.; et al. Honokiol blocks and reverses cardiac hypertrophy in mice by activating mitochondrial Sirt3. Nat. Commun. 2015, 6, 6656. [CrossRef] [PubMed]

(C) 2020 by the authors. Licensee MDPI, Basel, Switzerland. This article is an open access article distributed under the terms and conditions of the Creative Commons Attribution (CC BY) license (http://creativecommons.org/licenses/by/4.0/). 